\title{
Progress and prospect of research on forest landscape model
}

\author{
DAI Erfu' ${ }^{1}$, WU Zhuo ${ }^{1,2}$, WANG Xiaofan ${ }^{1,2}$, FU Hua $^{3}$, XI Weimin $^{4}$, PAN Tao $^{1}$ \\ 1. Key Laboratory of Land Surface Pattern and Simulation, Institute of Geographic Sciences and Natural Re- \\ sources Research, CAS, Beijing 100101, China; \\ 2. University of Chinese Academy of Sciences, Beijing 100049, China; \\ 3. College of Resource Environment and Tourism, Capital Normal University, Beijing 100048, China; \\ 4. Department of Biological and Health Sciences, Texas A\&M University, Kingsville, Texas 78363, USA
}

\begin{abstract}
The Forest Landscape Model (FLM) is an efficiency tool of quantified expression of forest ecosystem's structure and function. This paper, on the basis of identifying FLM, according to the stage of development, summarizes the development characteristics of the model, which includes the theoretical foundation of mathematical model, FLM of stand-scale, primary development of spatial landscape model, rapid development of ecosystem process model as the priority, and developing period of structure and process driven by multi-factor. According to the characteristics of different FLMs, this paper classifies the existing FLM in terms of mechanism, property and application, and elaborates the identifications, advantages and disadvantages of different types of models. It summarizes and evaluates the main application fields of existing models from two aspects which are the changes of spatial pattern and ecological process. Eventually, this paper presents FLM's challenges and directions of development in the future, including: (1) more prominent service on the practical strategy of forest management's objectives; (2) construction of multi-modules and multi-plugin to satisfy landscape research demand in various conditions; (3) adoption of high resolution's spatial-temporal data; (4) structural construction of multi-version module; (5) improving the spatial suitability of model application.
\end{abstract}

Keywords: Forest Landscape Model (FLM); development stage; model classification; model application; model development

\section{Introduction}

Forest, as a diverse and complex ecosystem on land surface, possesses important function of ecosystem service; meanwhile, it can not only provide abundant wood, healthy and suitable living environment for human beings, but also play a vital role in maintaining the stability of

Received: 2013-07-29 Accepted: 2014-04-08

Foundation: The National Basic Research Program of China (973 Program), No.2015CB452702; No.2012CB416906; National Key Technology R\&D Program, No.2013BAC03B04; National Natural Science Foundation of China, No.41371196

Author: Dai Erfu (1972-), PhD and Professor, specialized in comprehensive study of physical geography, climate change and regional response, simulation of LUCC. E-mail: daief@igsnrr.ac.cn 
global climate and protecting biological diversity and other terms. In terms of research on the structure and function of forest ecosystem, comprehensive research on both multi-space scale including tree species, forest stand, landscape and ecosystem, and multi-time scale combined the past, present and future, are gradually important. Adopting field observation and experiment data on forest landscape research cannot satisfy the demand, especially in some places, the field observation cannot realize the goal. Otherwise, the development of forestry, landscape ecology, geography, spatial information technology, mathematics, experimental science and other subjects provide references for intensive study of forest landscape. It is significant to analyze the development, characteristics and major application of the FLM for the development of landscape ecology. Theoretically, we can learn that how an important role the FLM plays in expanding related basic theories of landscape ecology at different stages. From practical aspect, understanding how to use the model to simulate the pattern and process of landscape can help us to apply the FLM to manage and develop forest. This can serve the sustainable development of forest.

Based on landscape biology and quantitative ecology theories, the landscape model uses computer simulation and GIS (geographic information system) technologies to help us establish a relationship between the structure, function and process of the landscape, and it is an efficient tool for predicting the future change of the landscape (Fu et al., 2011). As an important part of landscape model, FLM had a great development in the past 40 years. Based on ecological succession, disturbance, equilibrium and non-equilibrium theories, FLM combines the species competition and synergies in the forest ecosystem to quantitatively express the spatial distribution of species, forest communities, dynamic change of specie combination and interaction between them. Through simulating, researchers can use mathematics equations, logical algorithms, and computer simulation technologies to express the natural and human effects on the simulating process, which can be used for the research in the large spatial and temporal scale (He, 2008). FLM develops from simple mathematics equations to complex computer simulation models, from static forest stand-scale models to dynamic disturbance landscape-scale models. With the development of model structures and functions, more and more types of models are appearing. Meanwhile, the applied range is expanded as well.

This paper is mainly about the concept, development, classification and application of FLM. Based on the concept definition, this paper analyses the characteristics of FLM in different development phases, summarizes FLM classification and clarifies the application of FLM from the aspect of landscape pattern and process. At the end, this paper gives advices for the future development of FLM.

\section{Development of FLM}

Since the 1970s, FLM has been developed for more than 40 years. From the early theory construction and math differential equation to the later computer model, its development reflects the great progress of forest ecology and landscape ecology (Mladenoff et al., 1999; Perry et al., 2008). In different development phases, FLM shows different characteristics. In the aspects of key points, spatial scale, and complexity, FLM develops progressively (Figure 1). 


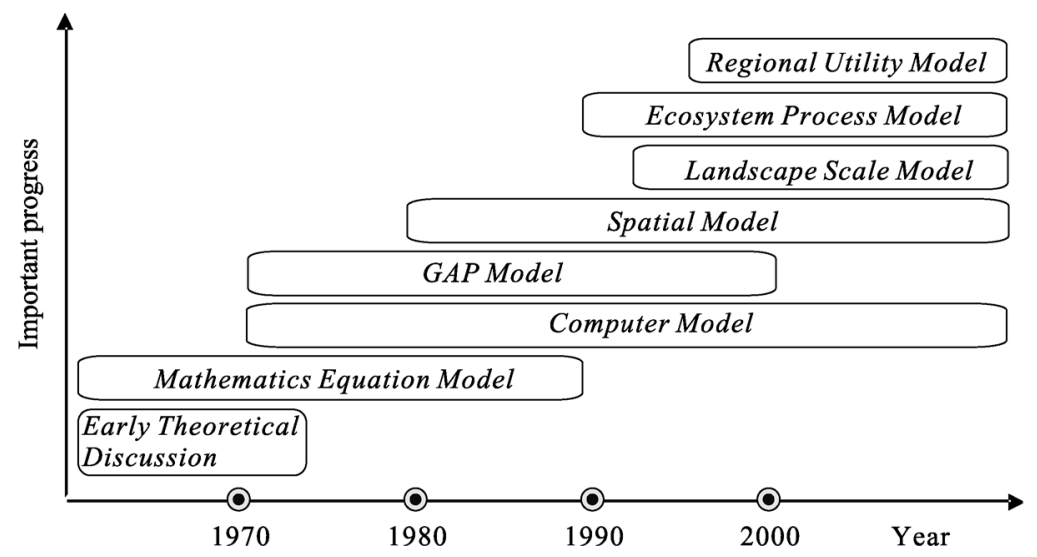

Figure 1 Development stage of FLM

\subsection{Concept definition of FLM}

FLM develops with the development of forestry, landscape ecology, spatial analysis technology, and analogy procedures. Different researchers define FLM from different angles. Here list some typical definitions:

(1) Mladenoff and Baker (1999) think FLM is a computer model, which can simulate the change of the forest landscape in different spatial and temporal scales.

(2) Scheller and Mladenoff (2007) think FLM is a computer program showing that forest landscape changes with time. Its purpose is representing the interaction between the future forest landscape and pattern.

(3) He (2008) thinks FLM can predict the spatial feature change of the simulated object, and simulate a spatiotemporal characteristic of at least one recurrent of spatial processes in a spatially interactive manner. It can implement spatial process repeat and is suitable for the simulation of the landscape spatial process in large spatial and temporal scale.

(4) Xi et al. (2009) think FLM can simulate and predict the forest spatial-temporal change characteristics in landscape scale on the basis of forest dynamic mechanism and disturbing influence. It also contains the following characteristics: predicting the forest spatial-temporal change characteristics in landscape scale, simulating the interaction between spatial processes, and predicting the long-term interaction between multiple factors.

In conclusion, different researchers have different definitions for FLM due to different research eras, depth, and concerns. Table 1 shows the difference.

From the preceding comparison, we can see that inchoate researchers normally use brief words to express basic characteristics of FLM, but are lack of considering the basic framework and usage range of the model. As the research becomes deeper, more professional nomenclatures will be used for describing the concept of FLM.

\subsection{Before the 1970s: mathematics model theoretical foundation}

As the limitations of computing capabilities and technical conditions at that period of time, the landscape process cannot be simulated by a computer. Therefore, early FLM researches were focusing on the theoretical discussion related to population, community, or land- 
Table 1 Comparison of different conceptions defined for FLM

\begin{tabular}{cll}
\hline Definer & \multicolumn{1}{c}{ Advantage } & \multicolumn{1}{c}{ Shortage } \\
\hline $\begin{array}{c}\text { Mladenoff and Baker } \\
\text { (1999) }\end{array}$ & $\begin{array}{l}\text { Simple and clear; strong generality; applica- } \\
\text { tion range }\end{array}$ & $\begin{array}{l}\text { Weak professionalism and perti- } \\
\text { nence; overemphasizing on computer } \\
\text { program; restrictive }\end{array}$ \\
$\begin{array}{c}\text { Scheller and Mladenoff } \\
\text { (2007) }\end{array}$ & $\begin{array}{l}\text { Simulation in landscape scale (interaction } \\
\text { between process and pattern) }\end{array}$ & $\begin{array}{l}\text { No application range; overemphasiz- } \\
\text { ing on the simulation essence of } \\
\text { computer program; restrictive }\end{array}$ \\
He (2008) & $\begin{array}{l}\text { Emphasizing on characteristics of spatial } \\
\text { variation; using mathematics models to simu- } \\
\text { late landscape-scale characteristics; interac- } \\
\text { tion between driving factors }\end{array}$ & $\begin{array}{l}\text { Insufficient analysis on landscape } \\
\text { variation characteristics in temporal } \\
\text { scale }\end{array}$ \\
& $\begin{array}{l}\text { Highlighting the relationship between forest } \\
\text { dynamic mechanism and disturbance influ- } \\
\text { ence, and the relationship between ecology } \\
\text { process and models }\end{array}$ & $\begin{array}{l}\text { Insufficient consideration on scale } \\
\text { extension }\end{array}$ \\
\hline Xi et al. (2009) & & \\
\hline
\end{tabular}

scape-based ecological succession, disturbance, equilibrium and non-equilibrium. On this basis, some mathematics equations were proposed to simulate biotic population dynamics, such as McKendrick-Von Foerster equation (McKendrick, 1925; Von Foerster, 1959), Multivariate versions equation (Sinko et al., 1967; Sinko et al., 1969; Streifer, 1974; Oster et al., 1974), etc. There is one model needs to be specially mentioned -- Stationary Markov model (Feller, 1968), which is a discrete and random mathematics model. It uses the realistic condition and development trend in a certain system to predict future conditions. So far, this model is still applied in multiple fields. Continuous improvement and perfection of these models lay a solid foundation for the FLM development.

\subsection{In the 1970s: forest stand-scale FLM}

In this period of time, large-scale integrated circuit computers had a great development. Some mathematics models had a further development as well. With computing technologies being applied in ecological simulation, computer models used for simulating forest landscape became the main developmental trend of models. This type of model was a milestone compared with the former mathematics equation. However, what most ecologists in this period focus on were the forest management issues of small scale forest section and small watershed forest land (Botkin et al., 1972). Therefore, FLM was mainly used to simulate the forest landscape change in stand-scale. This was called GAP model or forest stand dynamic model. From the development perspective, GAP model could be regarded as the first generation computer simulation model. It could simulate the forest dynamic change of all independent tree varieties using the empirical relationship of their appearance, growth, competition and mortality (Botkin et al., 1972; Shugart, 1984). JABOWA model that simulates forest constitute dynamic characteristics (Botkin et al., 1972), further improved FORET model (Shugart et al., 1977), and SORTIE model that can express spatial clarity (Pacala et al., 1996; Pacala et al., 1993) were all typical GAP models.

\subsection{In the 1980s: primary development of spatial landscape model}

In this period of time, fast development of computing power, processing power and software 
programming language provided great support for developing multiple-scale simulation models. Additionally, as remote sensing data and spatial analysis technologies also had been developed, ecologists did not only satisfied with the simulation of stand-scale forest landscape, but also looked forward to the spatial landscape models. As a result, mosaic model and element model appeared. Some typical models like the hypothetical grid-cell model invented by Franklin and Forman (1987), which is used for deforestation. This model can simulate the forest change in different deforestation modes. Perfected JABOWA model (Botkin et al., 1972) and its sub-models are also typical (Shugart et al., 1981; Gardner, 1987). The spatially explicit model can be applied in agricultural production, secondary forest succession (Wilkie et al., 1988), and coastal wet land change (Browder et al., 1985; Sklar et al., 1985), etc. Meanwhile, former FLMs were enhanced in spatial simulation, such as development and wide application of Markov chain and semi-Markov chain models (Collins et al., 1974; Collins, 1975; Hulst, 1979; Pickles, 1980; Henderson et al., 1975; Wilkins, 1977), further development of GAP model-FORET (Shugart, 1984), wildland fire behavior and fuel model-BEHAVE (Andrews, 1986; Andrews and Chase, 1989) and so on. At the same time, mathematical thoughts extracted from the cellular automata model (Wolfram, 1984) and neighborhood-based transition model (Turner, 1988) is adopted in building spatial landscape models. But, development and usage for large-scale spatial landscape models was still a difficulty (Baker, 1989).

\subsection{In the 1990s: ecosystem process model-based rapid development}

Ecosystem process model-based fast development is the main developmental trend of FLM in the 1990s (Running et al., 1991; Rastetter et al., 1991; Aber et al., 1992). Like LANDIS (Mladenoff et al., 1993; Mladenoff, 1996), LANDSIM (Mladenoff et al., 1999), FORMOSAIC (Liu et al., 1998), and DELTA (Mladenoff et al., 1999), they are all typical models in this period of time. These can not only trace the change characteristics of each independent tree variety, but also can simulate the ecological process, material circulation, and energy flow. Starting from spatial interaction, these models simulate the pattern and spatial process of the forest ecosystem, which can be used to research the ecological succession under long-term disturbance and analyze the change of forest landscape characteristics with time, such as change of landscape types and landscape heterogeneities. Compared with the GAP model, these models can simulate the change in landscape and ecosystem scale (Urban et al., 1991). The model combining FLM, satellite image, and GIS also appeared, like FOREST-BGC (Running et al., 1991) and PnET (Aber et al., 1992). This type of model regards remote sensing and geographic information spatial data set as the input data, and then integrates pixels to simulate the forest change in landscape scale. FLM in this period of time had a great development, especially on the simulation in landscape scale. However, even all kinds of models appeared, some of them just focused on the complexity of structure and operating. As a result, the operability and operating rate were reduced. Their application range was limited.

\subsection{In the 21st century: equal development of structure and process with multi-factor drive}

With the development of forest ecology, landscape ecology, remote sensing and GIS spatial 
analysis, and computing, the development of FLM in this period of time laid equal stress on multi-factor, structure and function. iLand (Seidl et al., 2012), TreeMig (Lischke et al., 2006), LandClim (Schumacher et al., 2006), and LANDIS-II (Scheller et al., 2007) are all typical models. In these models, LANDIS-II model is based on the LANDIS model. It is used to simulate succession, seed spread, disturbance, and management of forest landscape. It can implement the forest landscape change simulation at large spatial scale (Mladenoff, 2004). On the background of global climate change, ecologists paid more attention to the research of global ecosystem and biosphere. As a result, the global land biosphere modelIBIS model (Foley et al., 1996) and the TEM-LPJ model (Pan et al., 2002) simulating ecological process and disturbance effects of the multiple vegetation area appeared.

\section{Classification of FLMs}

The classification of FLMs is a summary for existing models according to different standards, it analyses the simulating processes, characteristics, inheritance relationships, and application targets of different models. This provides a solid foundation for the research of future models. By carding the existing FLMs, this paper gives nine types of classification schemes. Table 2 shows that different scholars have different understandings for the classification standard. For instance, Baker (1989) focused on the change scope of landscape; Keane et al. (2004) focused on the quantitative expression of models; Horn and Shugart (1989) focused on the development target of models; Perry and Enright (2006) focused on the simulated spatial scale; Scheller and Mladenoff (2007) focused on the ecological significance of models; He (2008) focuses on the space-time process and the relationship between it and site conditions; while Xi et al. (2009) focused on the operational mechanism of models.

By analyzing the preceding characteristics of different FLMs, this paper argues that three aspects need to be considered for the classification: model mechanism, model property, and model use. Mechanism indicates the fundamental of model development and model operating. Property indicates the features and functions of models. Use indicates the development purposes and usage range of models. Through these three dimensionalities, considering the simulating process, characteristics, and inheritance relationships of models, the classification result is adjusted to divide the models with a same inheritance relationship into the same type. This kind of classification standard can ensure the united classification standard, meanwhile, the qualitative analytical method was used to estimate the result. It is an accurate and scientific classification scheme.

\section{Application of FLMs}

As an effective tool to research the landscape change, FLM is widely used in many fields, such as forest management, watershed management, ecosystem structure, ecosystem process research, forest resource exploitation and utilization, climate change effect and response. In view of the landscape ecology, FLM is mainly used to research the spatial pattern variation of forest landscape and ecological process variation. The forest landscape pattern indicates the constituent ecosystem or the shape, proportion, and spatial arrangement of land use/land 


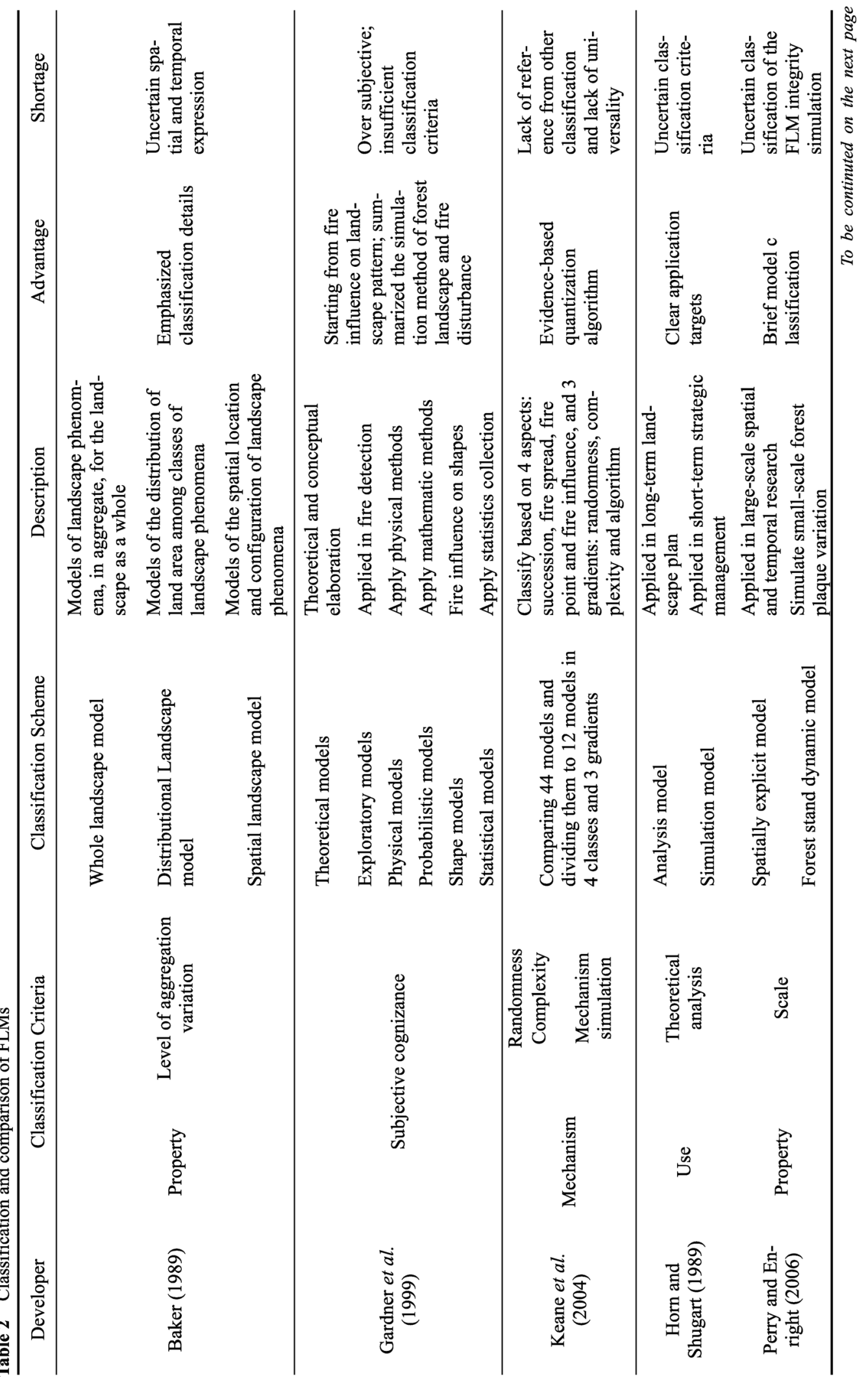


نั

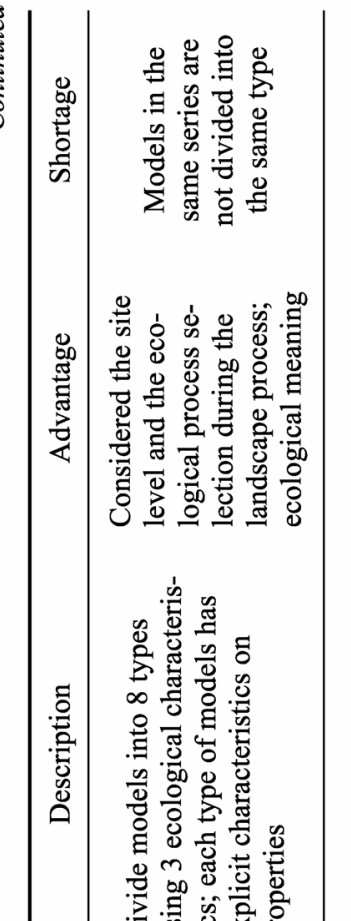

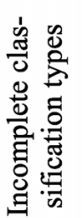

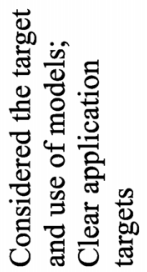

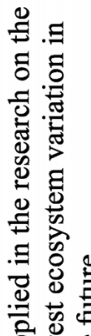
安过

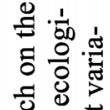 \\ 政施

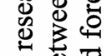

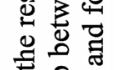 \\ 氞䱾

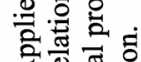

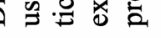

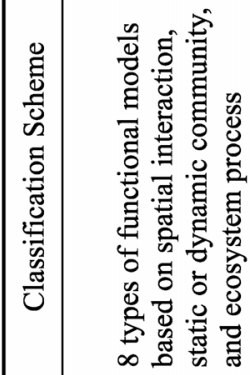

:

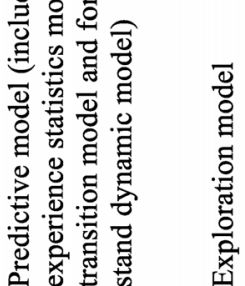

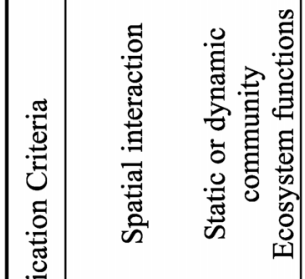

过

|
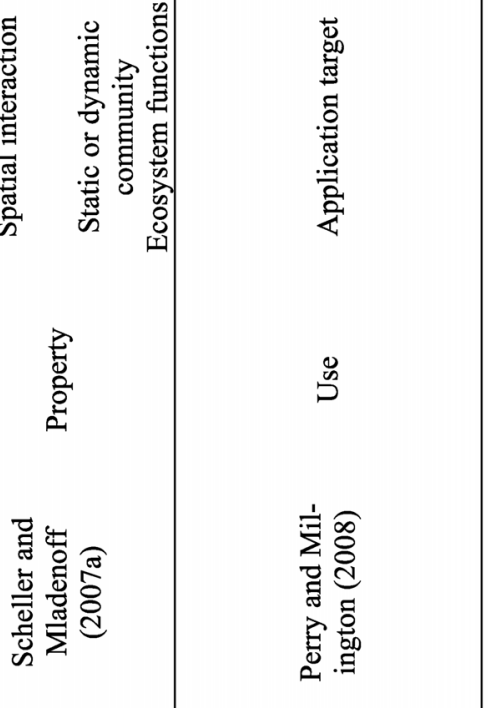

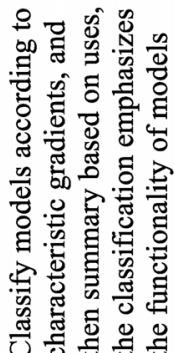
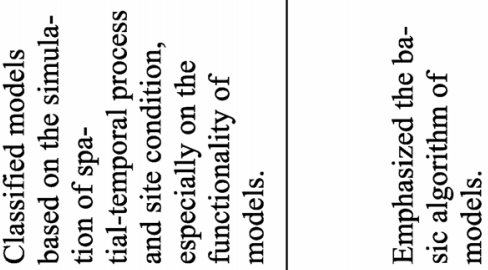

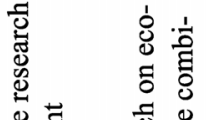

芯

兽 壱

ते

兽

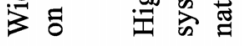

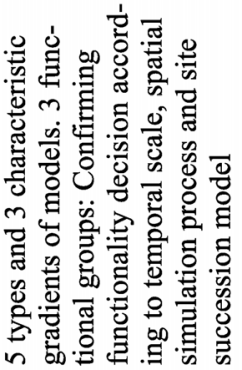

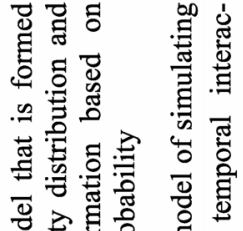

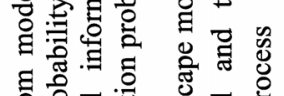

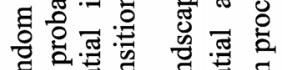

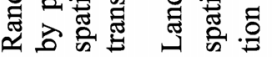

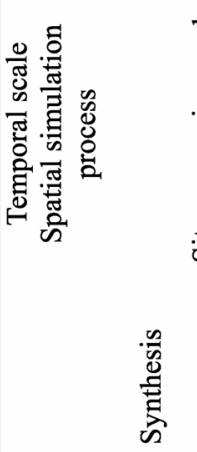

$\frac{0}{0}$
$\frac{0}{0}$
$\frac{0}{3}$
$\frac{0}{3}$
$\frac{0}{\pi}$

量

ஓ્ণ

$\underset{\substack{0 \\ ٍ}}{\stackrel{0}{0}}$ 
cover, which constitute the forest landscape. The forest landscape ecological process indicates the flow, migration, and transformation of materials, power, and information inside the forest ecosystem or among ecosystems. Simultaneously, the landscape pattern and ecological process are interdependent and interacted, and scale-dependence exists between them. Thus, in the practical application, pattern and process are emphasized respectively sometimes, while they are equally emphasized sometimes. To master model with scale changes in the law and the dependence on the scale, more and more attention has been paid to systematic analysis of each model in the study of patterns and processes in different areas of the simulation accuracy in order to explore the applicability of different models. Summarizing the application of FLM in recent years, it can be seen that the major applications are focused in the European and American countries (Figure 2).

\subsection{Research for forest landscape pattern}

On the forest landscape pattern, FLM is mainly used in forest composition change, structure change, effects of disturbance, and forest operating management. In this respect, a large number of research results are published. For example, Botkin et al. (1972) used the JABOWA model to analyze the relationship between forest environmental elements and forest growth in the past 200 years of the Hubbard Brook forest in New Hampshire, USA. Additionally, they simulated the secondary succession, competition, and vegetation variation of the forest. This model was mainly suitable for small-scale range of the forest gap simulation. The FORMAN model developed by Chen and Twilley (Chen et al., 1998) was used to study the long-term dynamics of mangrove forest development in south Florida in the USA. The FORMOSAIC model developed by Liu and Ashton (1998) was used to study the forest landscape variation in Malaysia. Seidl et al. (2012) used their iLand model to simulate the forest dynamics in landscape scale of Oregon, USA. The result checked the model's capacity of simulating landscape-scale forest ecosystem dynamics in the complex process. This model was applied to large-scale range of the simulation. In simulation of the Alps, the TreeMig model compared the spatial-temporal change in the forest stand scale and landscape scale. The result showed that the biomass of certain species has a high rate change in a small-scale landscape pattern, while environmental elements became the major factors to drive landscape pattern change in a large-scale landscape (Lischke et al., 2006). This study was significant in the study of model scale test.

Natural and human disturbance has a big effect on the forest landscape pattern. Normally, the disturbance process is the landscape change process under the action of multi-factor. Therefore, the disturbance plays a very important role in the FLM. A large number of research results about the fire disturbance have been published, including the prediction for fire frequency and fire period (Ratz, 1995; Li, 2002), and improvement for historical and natural fire policy (Li, 2000; Wimberly, 2002; Keane et al., 2003; Nonaka et al., 2005; Thompson et al., 2006). Keane et al. (1996) used the FIRE-BGC model to simulate the long-term dynamic of coniferous forest landscape in the northern part of Rocky Mountains, USA, and compared it with the dynamic of the U.S. white bark pine under different fire policies in the past 200 years. Hargrove et al. (2000) studied the fire influence of the plateau section in the Yellowstone National Park using the EMBYR model. They simulated the influence of different fire intensities and fire probabilities that were formed by climate and 


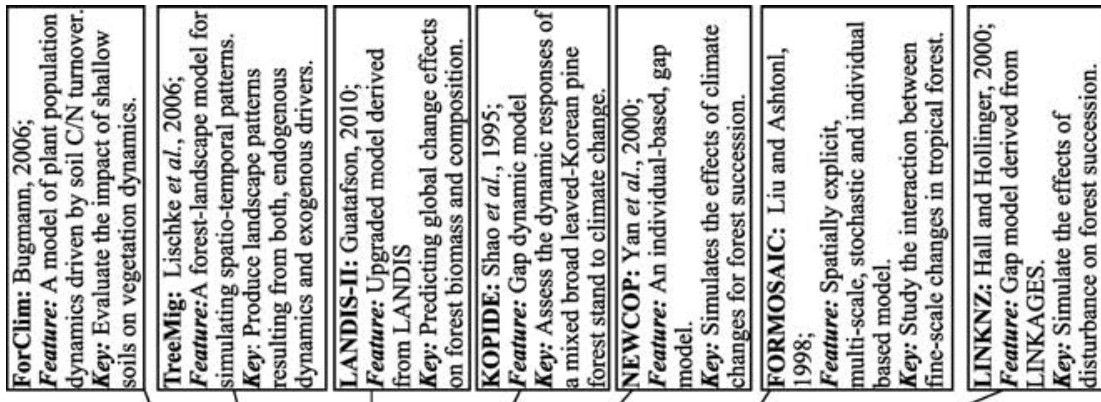

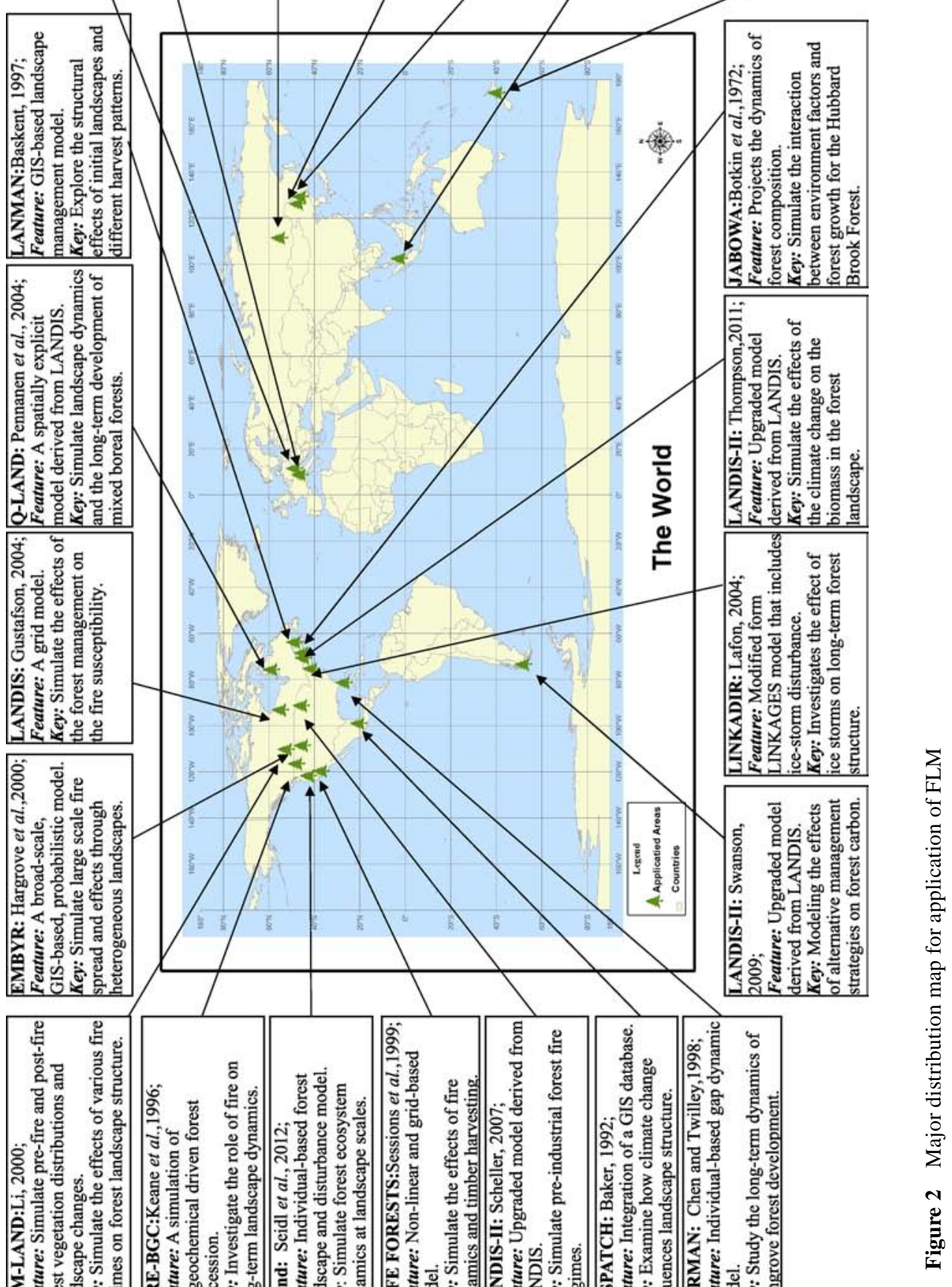


fuel debris for landscape heterogeneity in four scenarios. Hardy et al. (2001) used the FRCC model with the historical fire data and vegetation data to simulate the forest risks under different fire policies, and then serve the local forest management. The fire expectation SEM-LAND model invented by Li (2000) was used to simulate different fire policies' influence on the forest landscape structure in the western part of Alberta in Canada. Meanwhile, many research results of the climate change, wind, and harvest interference on forest structure and process were published as well. For instance, Yan et al. (2000) developed the NEWCOP model and used it to simulate the climate change influence on the Korean pine forest succession in the northeast of China. Lafon (2004) used the LINKADIR model to study the long-term influence that ice storm disasters take on the structure of the north hardwood forest in Adirondacks, New York, USA.

Forest management is also an important part of the FLM. The forest landscape management and resource evaluation model, DISPATCH, which was developed by Baker (1992), was used to simulate the climate variation influence on the landscape structure in Minnesota, USA. Baskent (1997) used the LANDMAN model to study characteristics of the original landscape structure and the fragmentation degrees in different harvest conditions in New Brunswick, Canada. Session et al. (1999) used the SAFE FORESTS model to analyze the influence of fire dynamic and harvest on the Sierra Nevada forest in California, USA. Then, the corresponding forest fire management and harvest policy could be made.

LANDIS and LANDIS-II models make a great process on the research and application of forest succession and forest structure pattern change. They can not only simulate the influence of fire, wind, and harvest on landscape pattern, but also can simulate the cycle accumulation of biomass and carbon. Gustafson et al. (2004) used LANDIS model to simulate the effects of the forest management on the fire susceptibility in northern Wisconsin. Thompson et al. (2011) simulated the effects of the climate change and land change on the biomass and constitute in the forest in the Massachusetts by using LANDIS-II model. Gustafson et al. (2011) used the LANDIS-II model to study how the forest management strategy mitigates the climate change in the south-central Siberia. Swanson (2009) used the LANDIS-II model to model the effects of alternative management strategies on forest carbon. Scheller et al. (2007) used the LANDIS-II model to simulate different kinds of disturbances, including fire, harvest, wind, and their influence on board-leaved forest in northern USA.

\subsection{Research for forest ecosystem process}

The ecological process application of FLM is mainly showed in material cycling process (like carbon and nitrogen cycles), species migration, interference process, and elements interaction. Shao et al. (1995) used the KOPIDE model to evaluate the dynamic influence of mixed broadleaf-conifer forest in Northeast China on the climate change and landscape dynamic variation. Hall and Hollinger (2000) used the LINKNZ model to simulate the forest succession process by analyzing the soil-water balance, decomposition rate, and nitrogen cycles of the original evergreen broadleaf forest in New Zealand. The Q-LAND model is developed based on the LANDIS model, which is the landscape process in site scale. On the basis of analyzing the site-scale tree amount and seed distribution, Pennanen et al. (2004) simulated the landscape long-term dynamic of the mingled forest in north Quebec, Canada. 
Pan et al. (2002) used the TEM-LPJ model to study the interaction of carbon, nitrogen, and water in larch forest, coniferous forest, and C3 grassland. Bugmann (1996) developed the ForClim model, which is a vegetation population dynamic model influenced by carbon-nitrogen cycles. It is used to study the dynamic variation process of the Alps forest structure in the past 1200 years.

Forest is a quite complex ecosystem. Pattern and process dynamic variation influence and depend each other. Therefore, the FLM is always used with these two factors. Especially since the 1990s, ecological process research is paid for attention. Amount of research results are used to study the FLM. At the same time, the application range of the FLM becomes wider and wider, extending from forest to other areas. This provides a powerful support for multi-disciplinary and interdisciplinary research.

\section{Progress and prospect of research on FLM}

The FLM can help scholars and managers study the variation of forest landscape pattern. However, like any other models, this type of model has a limitation as well. The development of FLM is a process in which the spatiotemporal scale, data availability and resolution, simulation result accuracy, parameterization degree, and simulation validation are chosen and balanced constantly (Mladenoff, 2004; Mladenoff et al., 1999; Rykiel, 1996; Syphard et al., 2004). Since the occurrence of FLM, there are two challenges: (1) The authenticity of research objects' spatial scale and simulation results, that is, if a true and valid result can be obtained after simulating a wide-range and long-term forest landscape structure and process. (2) How to verify the simulation results (He, 2011). Nowadays, there are two methods to verify the simulation results: (1) Compare different simulation scenarios (Rykiel, 1996). (2) Compare the simulation result with other results that are commonly accepted. This method requests expertise so that it has a limitation (Cary et al., 2006; Yang et al., 2007). (3) Compare the simulation result with the ecological experiment of long-term landscape scale or universal ecological theories. This method is used most widely (He et al., 2002; 2005).

In the context of global climate change, ecologists tend to focus more dynamic changes in the global forest ecosystems. Combined with the characteristics of current model of the 21st century, we believe the following points are necessary to be considered for the future development of the FLM:

(1) The practical applicability that mainly provides services for the target of forest management. As the forest becomes more and more important in the carbon sink process, applying a proper forest management measure to global warming becomes more and more valuable. Selecting an optimal forest management measure through a simulation can guarantee forest sustainable utilization, such as SAFE FORESTS (Session et al., 1999).

(2) Develop multi-module and multi-plugin models to meet the landscape research demand in a variety of conditions. In the 21st century, the development of landscape ecology presents comprehensive characteristic. It is the structure and function, pattern and process coupling. As the rapid development of computing technology, multi-module and multi-plugin models need to be developed to implement the comprehensive research on the structure and function, and extend the application range of models, such as LANDIS-II (Gustafson et al., 2011). 
(3) Use high-resolution spatial and temporal data. The high-resolution spatial and temporal data obtaining technology based on remote sensing image develops rapidly. The application of high-resolution spatial and temporal data based on the 3S technology makes the simulation result accuracy improvement, spatial and temporal scale extension, and structure analysis simulation possible.

(4) Establish the multi-version model structure and frame. The FLM needs to meet researchers', managers', and public's demands. Therefore, based on different users' expertise, using abilities, and differences in demand, establish the multi-version model structure and frame and develop different types of models to improve operations.

(5) Improve the application space suitability of models. It is hardly to find two totally same forest landscapes. As a result, research on the space suitability of different forest landscapes using only one model becomes harder and harder. Furthermore, the most basic development target of FLM is researching the landscape scale and function in multiple spatial and temporal scales. Therefore, to meet the research and management demands in different areas, the space suitability is necessary to be improved, such as TreeMig model (Lischke et al., 2006). Meanwhile, we should pay more attention to research on the data mining and analysis of the simulation result, including data analysis tools, data management methods, and visualization technology.

\section{References}

Aber J D, Federer C A, 1992. A generalized, lumped-parameter model of photosynthesis, evapotranspiration and net primary production in temperate and boreal forest ecosystems. Oecologia, 92(4): 463-474.

Andrews P L, 1986. BEHAVE: Fire behavior prediction and fuel modeling system-BURN subsystem, part 1. Ogden, UT, USA: Department of Agriculture, Forest Service, Intermountain Research Station.

Andrews P L, Chase C H, 1989. BEHAVE: Fire behavior prediction and fuel modeling system-BURN subsystem, part 2. Ogden, UT, USA: Department of Agriculture, Forest Service, Intermountain Research Station.

Baker W L, 1989. A review of models of landscape change, Landscape Ecology, 2(2): 111-133.

Baker W L, 1992. The landscape ecology of large disturbances in the design and management of nature reserves. Landscape Ecology, 7(3): 181-194.

Baskent E Z, 1997. Assessment of structural dynamic in forest landscape management. Canadian Journal of Forest Research, 27(10): 1675-1684.

Botkin D B, Bartley H A, Wallis J R, 1972. Some ecological consequences of a computer model of forest growth. Journal of Ecology, 60(3): 849-872.

Browder J A, Bartley H A, Davis K S, 1985. A probabilistic model of the relationship between marshland-water interface and marsh disintegration. Ecological Modelling, 29(1): 245-260.

Bugmann H K M, 1996. A simplified forest model to study species composition along climate gradients. Ecology, 77(7): 2055-2074.

Cary G J, Keane R E, Gardner R H et al., 2006. Comparison of the sensitivity of landscape-fire-succession models to variation in terrain, fuel pattern, climate and weather. Landscape Ecology, 21(1): 121-137.

Chen R, Twilley R R, 1998. A gap dynamic model of mangrove forest development along gradients of soil salinity and nutrient resources. Journal of Ecology, 86(1): 37-51.

Collins L, 1975. An Introduction to Markov Chain Analysis. Concepts and Techniques in Modern Geography. Norwich: Geo Abstracts, Univ. of East Anglia.

Collins L, Drewett R, Ferguson R, 1974. Markov models in geography. The Statistician, 23: 179-209.

Feller W, 1968. An Introduction to Probability Theory and Its Applications. New York: Wiley.

Foley J A, Prentice I C, Ramankutty N et al., 1996. An integrated biosphere model of land surface processes, 
terrestrial carbon balance, and vegetation dynamics. Global Biogeochemical Cycles, 10(4): 603-628.

Franklin J F, Forman R T T, 1987. Creating landscape patterns by forest cutting: Ecological consequences and principles. Landscape Ecology, 1(1): 5-18.

Fu B J, Chen L D, Ma K M et al., 2011. The Principle and Application of Landscape Ecology. 2nd ed. Beijing: Science Press. (in Chinese)

Gardner R H, 1987. Assessing regional impacts of growth declines using a forest succession model. Journal of Environmental Management, 24: 83-93.

Gardner R H, Romme W H, Turner, M G, 1999. Spatial Modeling of Forest Landscapes: Approaches and Applications. Cambridge, UK: Cambridge University Press, 163-185.

Gustafson E J, Shvidenko A Z, Scheller R M, 2011. Effectiveness of forest management strategies to mitigate effects of global change in south-central Siberia. Canadian Journal of Forest Research, 41(7): 1405-1421.

Gustafson E J, Shvidenko A Z, Sturtevant B R et al., 2010. Predicting global change effects on forest biomass and composition in south-central Siberia. Ecological Applications, 20(3): 700-715.

Gustafson E J, Zollner P A, Sturtevant B R et al., 2004. Influence of forest management alternatives and land type on susceptibility to fire in northern Wisconsin, USA. Landscape Ecology, 19(3): 327-341.

Hall G M J, Hollinger D Y, 2000. Simulating New Zealand forest dynamics with a generalized temperate forest gap model. Ecological Applications, 10(1): 115-130.

Hardy C C, Schmidt K M, Menakis J P et al., 2001. Spatial data for national fire planning and fuel management. International Journal of Wildland Fire, 10(4): 353-372.

Hargrove W W, Gardner R H, Turner M G et al., 2000. Simulating fire patterns in heterogeneous landscapes. Ecological Modelling, 135(2): 243-263.

He H S, 2008. Forest landscape models: definitions, characterization, and classification. Forest Ecology and Management, 254(3): 484-498.

He H S, Hao Z, Larsen D R et al., 2002. A simulation study of landscape scale forest succession in northeastern China. Ecological Modelling, 156(2): 153-166.

He H S, Hao Z, Mladenoff D J et al., 2005. Simulating forest ecosystem response to climate warming incorporating spatial effects in north-eastern China. Journal of Biogeography, 32(12): 2043-2056.

He H S, Yang J, Shifley S R et al., 2011. Challenges of forest landscape modeling: Simulating large landscapes and validating results. Landscape and Urban Planning, 100(4): 400-402.

Henderson W, Wilkins C W, 1975. The interaction of bushfires and vegetation. Search, 6(4): 130-133.

Horn H S, Shugart H H, Urban D L, 1989. Simulators as models of forest dynamics. In: Perspectives in Ecological Theory. New Jersey: Princeton University Press: 256-267.

Keane R E, Cary G J, Davies I D et al., 2004. A classification of landscape fire succession models: Spatial simulations of fire and vegetation dynamics. Ecological Modelling, 179(1): 3-27.

Keane R E, Cary G J, Parsons R, 2003. Using simulation to map fire regimes: An evaluation of approaches, strategies, and limitations. International Journal of Wildland Fire, 12(4): 309-322.

Keane R E, Morgan P, Running S W, 1996. Fire-BGC: A mechanistic ecological process model for simulating fire succession on coniferous forest landscapes of the northern Rocky Mountains. Ogden, Utah: U.S. Department of Agriculture Forest Service, Intermountain Research Station.

Lafon C W, 2004. Ice-storm disturbance and long-term forest dynamics in the Adirondack Mountains. Journal of Vegetation Science, 15(2): 267-276.

Li C, 2000. Reconstruction of natural fire regimes through ecological modelling. Ecological Modelling, 134(2): 129-144.

Li C, 2002. Estimation of fire frequency and fire cycle: A computational perspective. Ecological Modelling, 154(1): 103-120.

Lischke H, Zimmermann N E, Bolliger J et al., 2006. TreeMig: A forest-landscape model for simulating spatio-temporal patterns from stand to landscape scale. Ecological Modelling, 199(4): 409-420.

Liu J, Ashton P S, 1998. FORMOSAIC: An individual-based spatially explicit model for simulating forest dynamics in landscape mosaics. Ecological Modelling, 106(2): 177-200. 
McKendrick A G, 1925. Applications of mathematics to medical problems. Proceedings of the Edinburgh Mathematical Society, 44: 98-130.

Mladenoff D J, 2004. LANDIS and forest landscape models. Ecological Modelling, 180(1): 7-19.

Mladenoff D L, Baker W L, 1999. Spatial Modeling of Forest Landscape Change: Approaches and Application. Cambridge, UK: Cambridge University Press.

Mladenoff D J, Host G E, Boeder J et al., 1993. LANDIS: A model of forest landscape succession and management at multiple scales. Oak Ridge, TN, USA: Proceedings of the Annual US Landscape Ecology Symposium, 77.

Mladenoff D J, Host G E, Boeder J et al., 1996. LANDIS: A spatial model of forest landscape disturbance, succession, and management. Second International Conference on Integrating GIS and Environmental Modeling. Santa Barbara, California: National Center for Geographic Information and Analysis, 175-179.

Nonaka E, Spies T A, 2005. Historical range of variability in landscape structure: A simulation study in Oregon, USA. Ecological Applications, 15(5): 1727-1746.

Oster G, Takahashi Y, 1974. Models for age-specific interactions in a periodic environment. Ecological Monographs, 44: 483-501.

Pacala S W, Canham C D, Saponara J et al., 1996. Forest models defined by field measurements: Estimation, error analysis and dynamics. Ecological Monographs, 66(1): 1-43.

Pacala S W, Hurtt G C, 1993. Terrestrial vegetation and climate change: Integrating models and experiments. Sunderland MA: Biotic Interactions and Global Change. Sinauer Associates, 57-74.

Pan Y, McGuire A D, Melillo, J M et al., 2002. A biogeochemistry-based dynamic vegetation model and its application along a moisture gradient in the continental United States. Journal of Vegetation Science, 13(3): 369-382.

Pennanen J, Greene D F, Fortin M J et al., 2004. Spatially explicit simulation of long-term boreal forest landscape dynamics: incorporating quantitative stand attributes. Ecological Modelling, 180(1): 195-209.

Perry G L W, Enright N J, 2006. Spatial modelling of vegetation change in dynamic landscapes, a review of methods and applications. Progress in Physical Geography, 30(1): 47-72.

Perry G L W, Millington J D A, 2008. Spatial modelling of succession-disturbance dynamics in forest ecosystems: Concepts and examples. Perspectives in Plant Ecology, Evolution and Systematics, 9(3): 190-210.

Pickles A, 1980. Models of movement: A review of alternative methods. Environment and Planning A, 12(12): 1383-1404.

Rastetter E B, Ryan M G, Shaver G R et al., 1991. A general biogeochemical model describing the responses of the $\mathrm{C}$ and $\mathrm{N}$ cycle in terrestrial ecosystems to changes in $\mathrm{CO}_{2}$, climate, and $\mathrm{N}$ deposition. Tree Physiology, 9(1/2): 101-126.

Ratz A, 1995. Long-term spatial patterns created by fire: A model oriented towards Boreal Forests. International Journal of Wildland Fire, 5(1): 25-34.

Running S W, Gower S T, 1991. FOREST-BGC, a general model of forest ecosystem processes for regional applications. II: Dynamic carbon allocation and nitrogen budgets. Tree Physiology, 9(1/2): 147-160.

Rykiel Jr E J, 1996. Testing ecological models: The meaning of validation. Ecological Modelling, 90(3): 229-244.

Scheller R M, Domingo J B, Sturtevant B R et al., 2007. Design, development, and application of LANDIS-II, a spatial landscape simulation model with flexible temporal and spatial resolution. Ecological Modelling, 201 (3): 409-419.

Scheller R M, Mladenoff D J, 2007. An ecological classification of forest landscape simulation models: Tools and strategies for understanding broad-scale forested ecosystems. Landscape Ecology, 22(4): 491-505.

Schumacher S, Reineking B, Sibold J et al., 2006. Modeling the impact of climate and vegetation on fire regimes in mountain landscapes. Landscape Ecology, 21(4): 539-554.

Seidl R, Rammer W, Scheller R M et al., 2012. An individual-based process model to simulate landscape-scale forest ecosystem dynamics. Ecological Modelling, 231: 87-100.

Sessions J, Johnson K N, Franklin J F et al., 1999. Achieving sustainable forest structures on fire-prone land- 
scapes while pursuing multiple goals. In: Spatial Modeling of Forest Landscapes Change: Approaches and Applications. Cambridge, UK: Cambridge University Press, 210-255.

Shao G F, Zhao S D, Shugart H H, 1995. Forest Dynamics Modeling. Beijing: Chinese Forestry Press. (in Chinese)

Shugart H H, 1984. A Theory of Forest Dynamics: The Ecological Implications of Forest Succession Models. New York: Springer-Verlag.

Shugart H H, Noble I R, 1981. A computer model of succession and fire response of the high-altitude Eucalyptus forest of the Brindabella Range, Australian Capital Territory. Australian Journal of Ecology, 6(2): 149-164.

Shugart H H, West D C, 1977. Development of an Appalachian deciduous forest succession model and its application to assessment of the impact of the chestnut blight. Journal of Environmental Management, 5: 161-179.

Sinko J W, Streifer W, 1967. A new model for age-size structure of a population. Ecology, 48: 910-918.

Sinko J W, Streifer W, 1969. Applying models incorporating age-size structure to Daphnia. Ecology, 50: 608-615.

Sklar F H, Costanza R, Day Jr J W, 1985. Dynamic spatial simulation modeling of coastal wetland habitat succession. Ecological Modelling, 29(1): 261-281.

Streifer W, 1974. Realistic models in population ecology. Advances in Ecological Research, 8: 199-266.

Swanson M E, 2009. Modeling the effects of alternative management strategies on forest carbon in the Nothofagus forests of Tierra del Fuego, Chile. Forest Ecology and Management, 257(8): 1740-1750.

Syphard A D, Franklin J, 2004. Spatial aggregation effects on the simulation of landscape pattern and ecological processes in southern California plant communities. Ecological Modelling, 180(1): 21-40.

Thompson J R, Foster D R, Scheller R M et al., 2011. The influence of land use and climate change on forest biomass and composition in Massachusetts, USA. Ecological Applications, 21(7): 2425-2444.

Thompson J R, Johnson K N, Lennette M et al., 2006. Historical disturbance regimes as a reference for forest policy in a multiowner province: A simulation experiment. Canadian Journal of Forest Research, 36(2): 401-417.

Turner M G, 1988. A spatial simulation model of land use changes in a piedmont county in Georgia. Applied Mathematics and Computation, 27(1): 39-51.

Urban D L, Acevedo M F, Garman S L, 1999. Scaling fine-scale processes to large-scale patterns using models derived from models: Meta-models. In: Spatial Modeling of Forest Landscape Change: Approaches and Applications. Cambridge, UK: Cambridge University Press, 70-98.

Van Hulst R, 1979. On the dynamics of vegetation: Markov chains as models of succession. Vegetatio, 40(1): 3-14.

von Foerster H, 1959. Some Remarks on Changing Populations. New York: The Kinetics of Cellular Proliferation. 382-407.

Wilkie D S, Finn J T, 1988. A spatial model of land use and forest regeneration in the Ituri forest of northeastern Zaire. Ecological Modelling, 41(3): 307-323.

Wilkins C W, 1977. A stochastic analysis of the effect of fire on remote vegetation. South Australia: PhD Diss., Univ. of Adelaide.

Wimberly M C, 2002. Spatial simulation of historical landscape patterns in coastal forests of the Pacific Northwest. Canadian Journal of Forest Research, 32(8): 1316-1328.

Wolfram S, 1984. Cellular automata as models of complexity. Nature, 311: 419-424.

Xi W M, Coulson R N, Birt A G et al., 2009. Review of forest landscape models: Types, methods, development and applications. Acta Ecologica Sinica, 29(1): 69-78.

Yan X D, Zhao S D, Yu Z L, 2000. Modeling growth and succession of northeastern China forests and its applications in global change studies. Acta Phytoecologica Sinica, 24(1): 1-8. (in Chinese)

Yang J, He H S, Shifley S R et al., 2007. Spatial pattern of modern period human-caused fire occurrence in the Missouri Ozark Highlands. Forest Science, 53(1): 1-15. 